\title{
Mechanical Performance of Cockle Shell Particles (CSP) and Oil Palm Fibre (OPF) Reinforced Epoxy Composite
}

\author{
Abdul Hamid Abdullah and Sujan Debnath

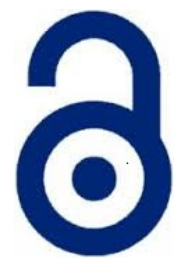 \\ Received: 15 August 2017 \\ Accepted: 13 September 2017 \\ Published: 15 September 2017 \\ Publisher: Deer Hill Publications \\ (C) 2017 The Author(s) \\ Creative Commons: CC BY 4.0
}

\begin{abstract}
The effects of particle sizes (range 1, 2 and 3) and particle loading (5wt\%, 10wt\%, 15wt\%, 20wt\% and 25wt \%) on the mechanical properties (tensile and flexural properties), water absorption properties and morphology analysis (optical microscope) of epoxy composites reinforced with cockle shell particles and hybrid epoxy based composite reinforced with cockle shell particles and oil palm fibres were investigated. Pre-chemical treatment of alkaline solution $(\mathrm{NaOH})$ with $5 \%$ concentration was used to treat the oil palm fibre prior to the fabrication of composite. Based on the findings, the composite with smaller size and lower loading of cockle shell particle showed higher improvement in mechanical properties. Meanwhile, the hybrid epoxy based composite reinforced with smaller size of cockle shell particle and oil palm fibre showed enhancement in mechanical properties. For water absorption analysis, cockle shell particle-epoxy composites with lower particle loading showed less water uptake.
\end{abstract}

Keywords. Cockle shell particle, oil palm fibre, epoxy composite

\section{INTRODUCTION}

There are various types of fibres and fillers that been used in the polymer composites such as glass, carbon, aramid, nylon, carbon black and silica etc. However, the movement towards environmentally sustainable engineering solutions has led to the rise of another class of composite material, commonly referred to as "green composites" that contain either naturally occurring and/or waste material as one of its component. The utilization of waste materials which are abundant and cheap, especially from clean resources, has become more popular nowadays. Seashell has been considered to be a good candidate to be used as a bio-filler for preparing polymer composites because it is inexpensive, abundant, environmental friendly and is a renewable resource. Moreover, it has very high content of calcium carbonate $\left(\mathrm{CaCO}_{3}\right)$ plus organic matrix. Calcium carbonate $\left(\mathrm{CaCO}_{3}\right)$ extracted from limestone, has been long been used as a filler in the plastic and rubber. However, the mining and quarrying of limestone is not very sustainable in the long term compared to seashell which is renewable resource. Moreover, the quarrying of limestone is damaging the landscape, producing smoke and dust plus deteriorating the water quality. The large consumption of cockles generating a large volume of shell waste which contributes to the deterioration of environment as it needs to be disposed at the landfill site. Recycling of shell waste is very good way to reduce the garbage that need to be processed at the landfill site, and offers an opening to develop this waste material into useful products. The aim of this study is to investigate the effect of different cockle shell particle loading and size reinforced polymer composites and the hybrid polymer based composites reinforced cockle shell particle and oil palm fibre in term of mechanical, water absorption and morphology properties.

\section{METHODOLOGY}

\subsection{Materials}

The cockle shells used were collected from restaurants, and the oil palm fibre is supplied by Sarawak Oil Palm Company. The cockle shell particles were extracted by grinding the shell using ball mill machine. While oil palm fibres were extracted from oil palm empty fruit bunch (OPEFB) through retting process. The epoxy resin was selected as matrix phase and hardener used as curing purposes from Miracon Sdn. Bhd was procured together.

\author{
A.H. Abdullah, D. Sujan $\square$ \\ CDT 250, Curtin University Malaysia \\ 98009 Miri, Sarawak, Malaysia \\ E-mail: d.sujan@curtin.edu.my
}

Reference: Abdullah, A.H., and Sujan, D. (2017). Mechanical Performance of Cockle Shell $\left(\mathrm{CaCO}_{3}\right)$ Powder and Oil Palm Fibre Reinforced Epoxy Composites. International Journal of Engineering Materials and Manufacture, 2(3), 58-66. 


\subsection{Preparation of Cockle Shell Particles}

The cockle shell particles were separated in three ranges size depending on size of the particles. Three series of samples (epoxy reinforced by cockle shell particles) were prepared:

- $\quad$ First series with 5, 10, 15, 20 and $25 \mathrm{wt} \%$ particles belonging to particles size $(\geq 63$ and $<212(\mu \mathrm{m})$ range 1 .

- Second series with 5, 10, 15, 20 and $25 w t \%$ particles belonging to particles size $(\geq 212$ and $<425$ ( $\mu$ m) range 2.

- Third series with 5, 10, 15, 20 and 25 wt\% particles belonging to particles size $(\geq 425$ and $<500$ ( $\mu$ m) range 3 .

\subsection{Fibre Treatment}

The oil palm fibres were treated with $5 \%$ concentration alkaline solution. Then, the fibres were immersed into $5 \%$ concentration of sodium hydroxide $(\mathrm{NaOH})$ for 5 hours at room temperatures. Subsequently, the fibres were washed with distilled water until the $\mathrm{pH} 7$ value was reached. Finally, the fibres were dried in an oven at $80{ }^{\circ} \mathrm{C}$ for 8 hours and then sealed in plastic bag.

\subsection{Fabrication of Composite}

Hand lay-up process was chosen in the fabrication of the composites. Prior to fabrication of Frekote 770-NC (release agent) was applied on the surface of the mould. The masses of $5 w t \%, 10 w t \%, 15 w t \%, 20 w t \%$ and $25 w t \%$ of cockle shell particles was prepared and measured. The ratio of epoxy resin to hardener was 100:30 according to the manufacturer guidelines. Then the cockle shell particles was mixed with epoxy resin and stirred thoroughly for 5 minutes until the filler was completely mixed with the resin by using scrap- rotate- scrap-mixing method. This method was to reduce the trapping of air bubbles. Next, was degasified using a vacuum chamber. After that, the mixture was poured into the mould and left for solidification. After solidification, composites were post-cured in an oven for 2 hours at $80^{\circ} \mathrm{C}$. For reference purpose, pure epoxy specimens were also fabricated.

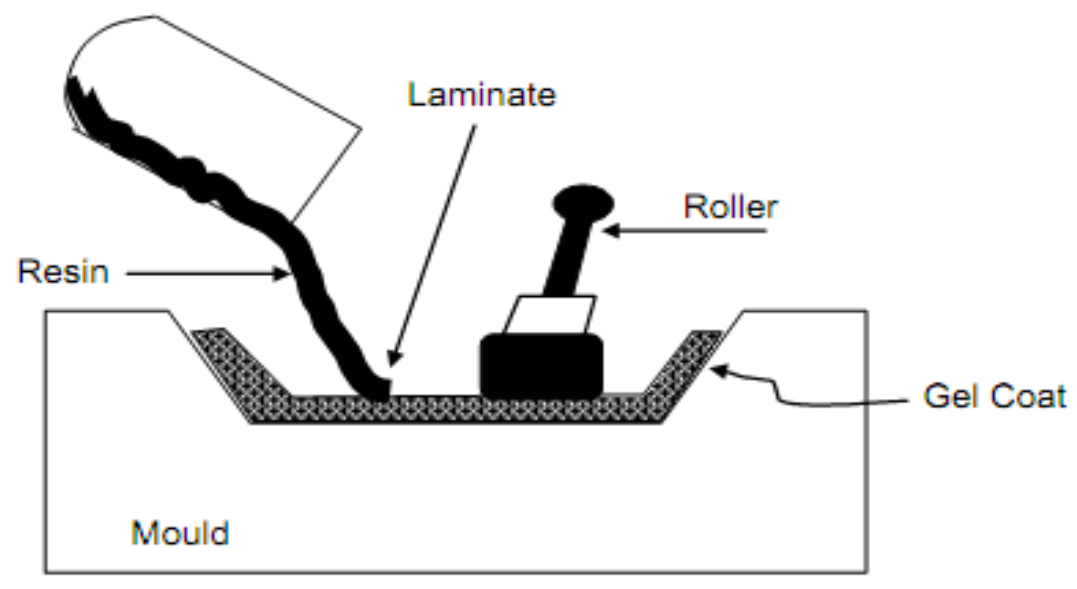

Figure 1: Hand lay- up technique [3]

\subsection{Mechanical Property Analysis}

The mechanical properties of the composites (tensile and flexural properties) were tested by using the universal testing machine. The tensile testing was conducted accordance to ASTM D638 while flexural testing was conducted accordance to ASTM D790. The crosshead speed was fixed at $5 \mathrm{~mm} / \mathrm{min}$ and $5 \mathrm{KN}$ of load cell was applied until the specimen was failed. Five identical specimens of every sample were used for each test.

\subsection{Water Absorption Property Analysis}

The water absorption of composite specimen was conducted accordance to ASTM D570. The initial weight of three identical composite specimens for each sample was recorded before immersed in the distilled water. The composite specimens were taken out from the distilled water for every 24 hours to study the water absorption for each specimen.

\subsection{Morphology Analysis}

The morphological analysis of the fracture surface of cockle shell particles-epoxy composites and cockle shell/oil palm fibres-epoxy composites were conducted by an optical microscope. By means of this observation, it restricted the view to only observe the dispersion and agglomeration of particles and fibre pull out of the composite specimen after fracture and the weak matrix bonding can also be seen. 


\section{RESULTS AND DISCUSSION \\ 3.1 Mechanical Property}

Figure 2 and Figure 3 illustrated the tensile and flexural strength for the composites as a function of particle loading. It was observed that decrease in tensile and flexural strength with the increasing of particle loading for all three different particle sizes composites. One of the factors for poor mechanical properties at higher particle loading was due to the poor adhesion between the epoxy resin and particles. This poor adhesion increases with the increasing of particle loading. This poor adhesion would lead to inefficient of stress transfer at the particle filled epoxy interface, thus caused de-bonding to occur and generates stress concentration and affects the particles not able to carry any load, finally accelerates the specimen of the composite to break. Furthermore, the poor dispersion of cockle shell particles, presence of void or porosity and de-wetting of epoxy resin inside the composite specimens, decreased the tensile and flexural strength of composite at higher particle loading by generating stress concentration points which lead to a crack initiation spot under the applied stress [4]. Moreover, decrease in tensile and flexural strength was observed when the particle size increases. This was due to particles with smaller size have a higher total surface area, thus providing higher strength of particles filled epoxy composites, in other words, tensile and flexural strength increase with the increasing of surface area filled particles, so a more effective stress transfer from the epoxy resin to the particles are able to be achieved [5]. Besides, increasing in particle size caused the reduction of wettability between the adhesion of particles and epoxy resin. Thus, the effectiveness number of bonds between particles and epoxy resin would decrease. Consequently, the surface area of compatibility would decrease, thus the tensile and flexural strength decrease with increasing particle size [6]. As referring to figure 4 and figure 5, it was observed that tensile and flexural modulus increase linearly with the increasing of particle loading until an optimum was reached. The improvement can be indicated to good adhesion between the particles- matrix.

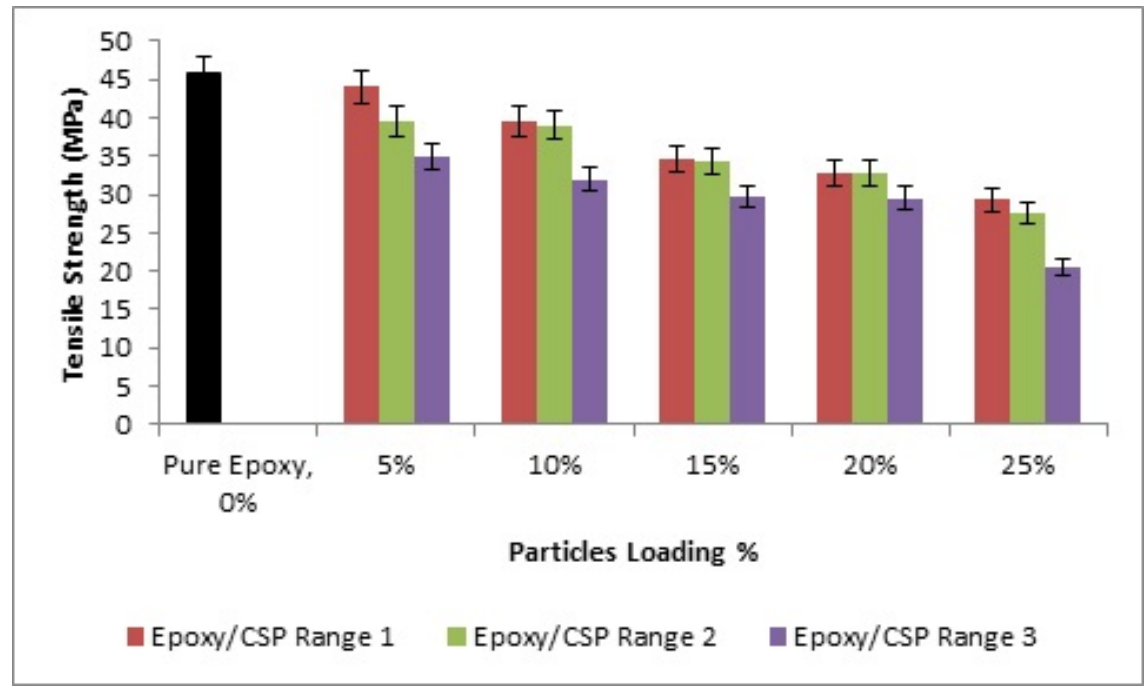

Figure 2: Tensile strength versus various particles loading

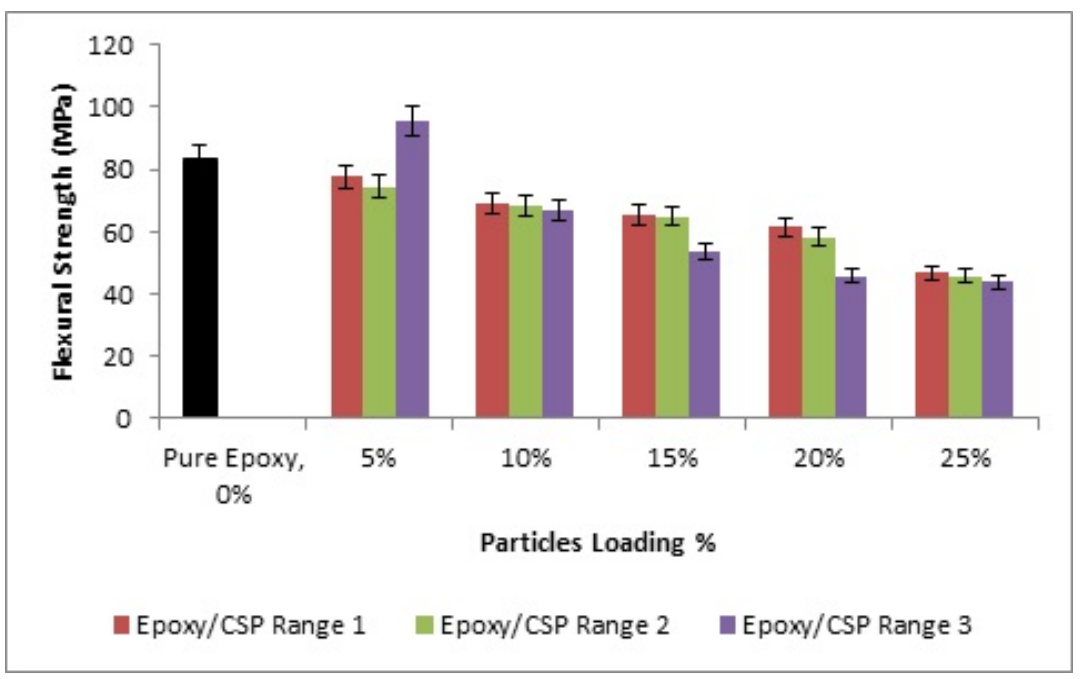

Figure 3: Flexural strength versus various particles loading 


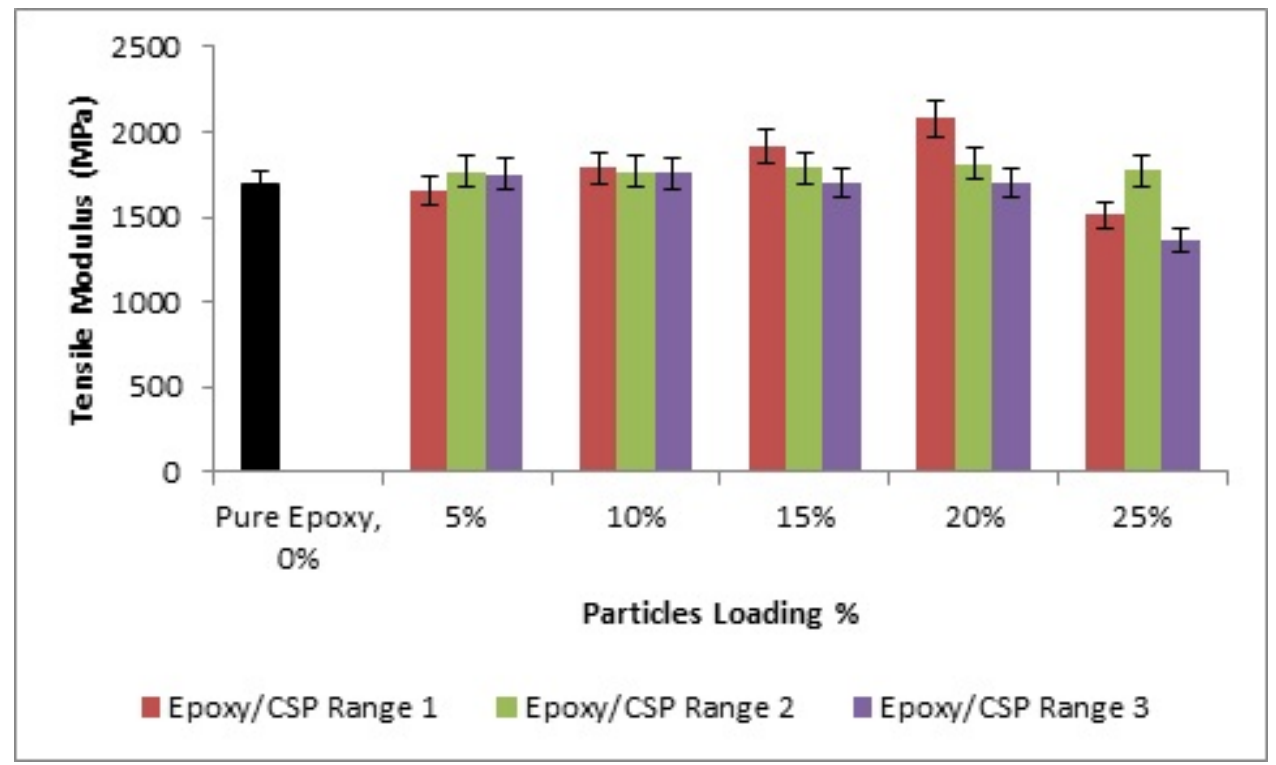

Figure 4: Tensile modulus versus various particles loading

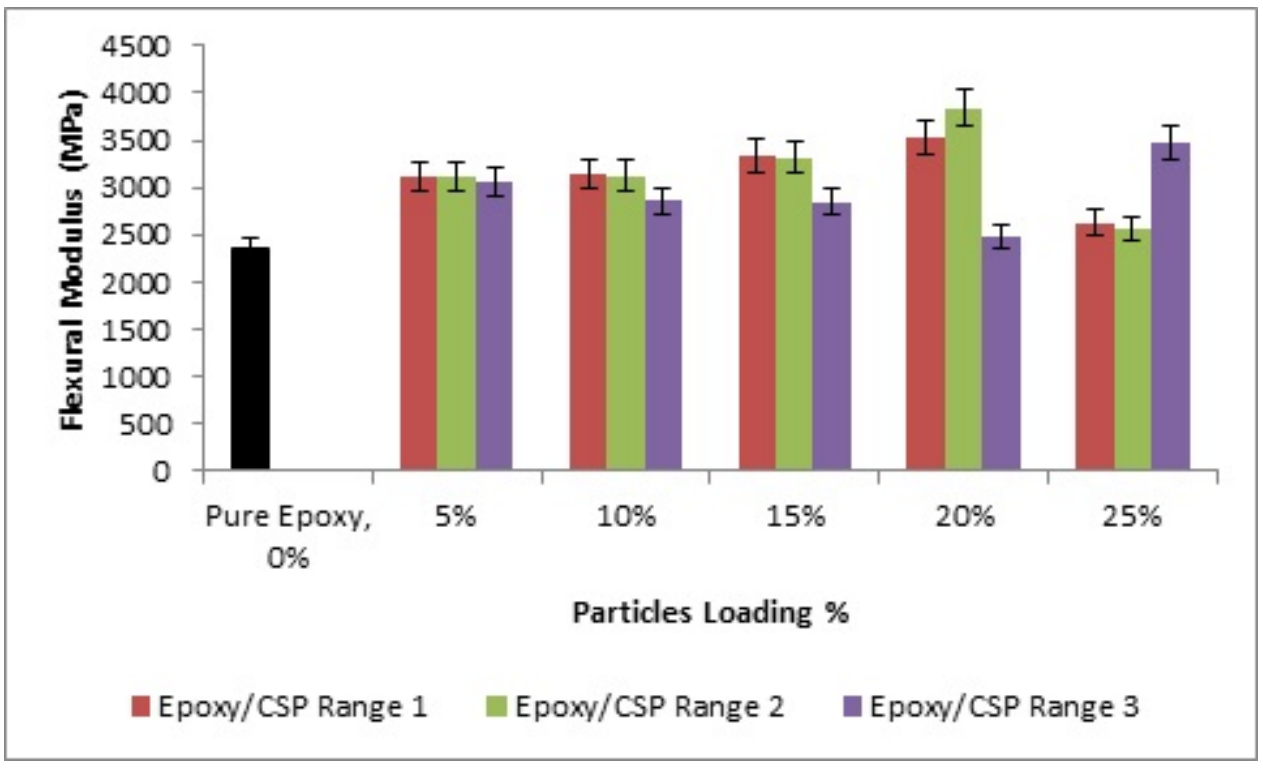

Figure 5: Flexural modulus versus various particles loading

Figure 6 and figure 7 illustrated the effect tensile and flexural strength on the cockle shell particle/oil palm fibre hybrid epoxy composites. It was observed that the tensile strength of hybrid composite is inversely proportional to the cockle shell particle size. According to figure 6, the tensile strength of hybrid composites with particles size in range 1 $(33.83 \mathrm{MPa})$ and range $2(28.03 \mathrm{MPa}$ ) showed an improvement of $35.3 \%$ and $21.9 \%$ respectively as compared to particles size in range $3(21.88 \mathrm{MPa})$. In the figure 7, the flexural strength with improvement of $54.3 \%$ and $47.8 \%$ was observed at composites with particles size in range $1(96.78 \mathrm{MPa})$ and range $2(84.74 \mathrm{MPa})$ as compared to particles size in range $3(44.21 \mathrm{MPa})$ respectively. Apart from that, it was also observed the flexural strength of hybrid composites were higher as compared to the cockle shell epoxy composites in range 1 and 2 respectively as shown in figure 7. For example, the flexural strength of hybrid composites in range 1 and 2 had increased $19 \%$ and $12 \%$ as compared to the cockle shell particles - epoxy composites in range 1 and 2 respectively. 


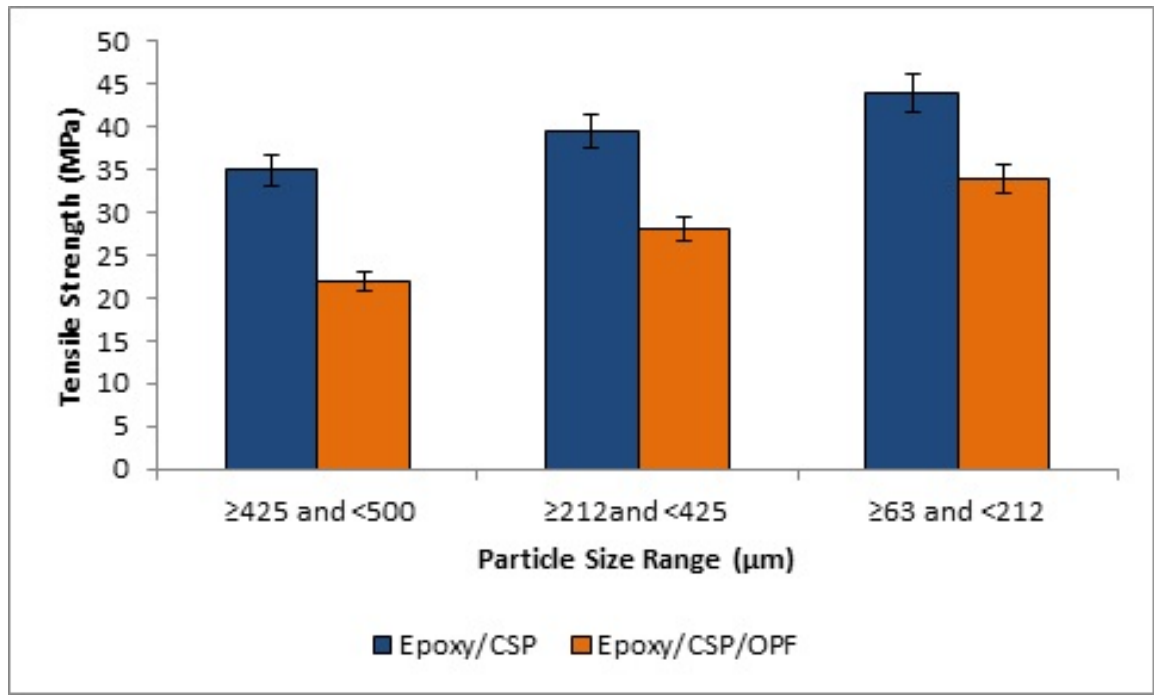

Figure 6: Tensile Strength of epoxy composites

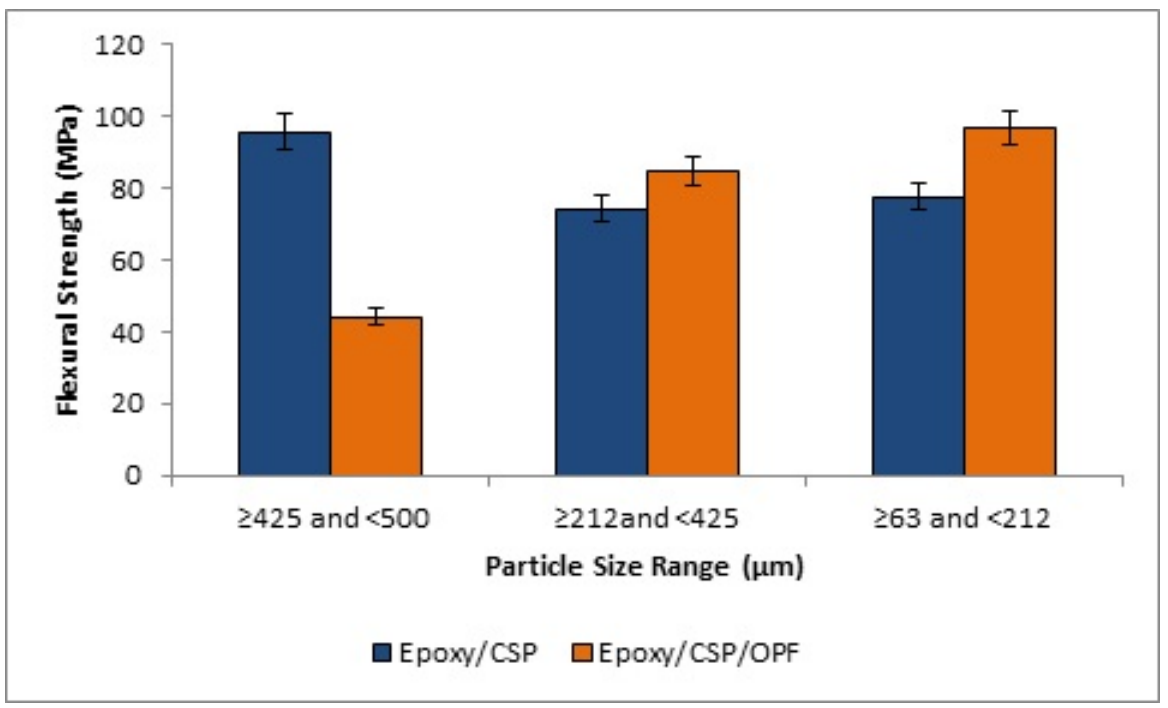

Figure 7: Flexural strength of epoxy composites

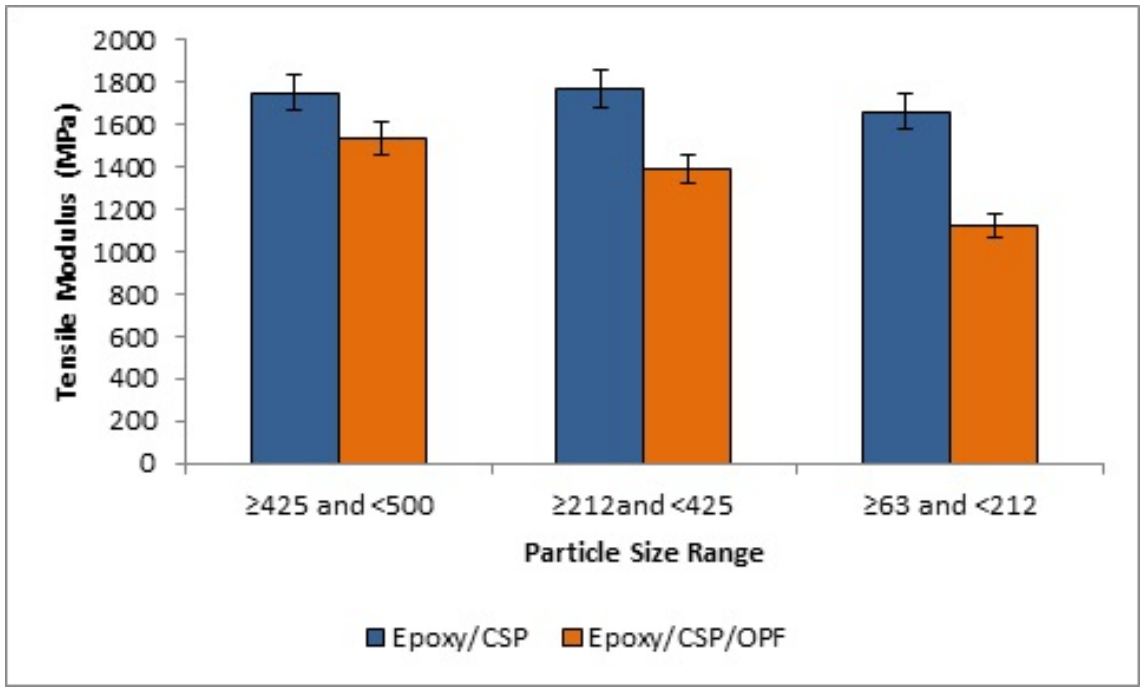

Figure 8: Tensile modulus of epoxy composites 


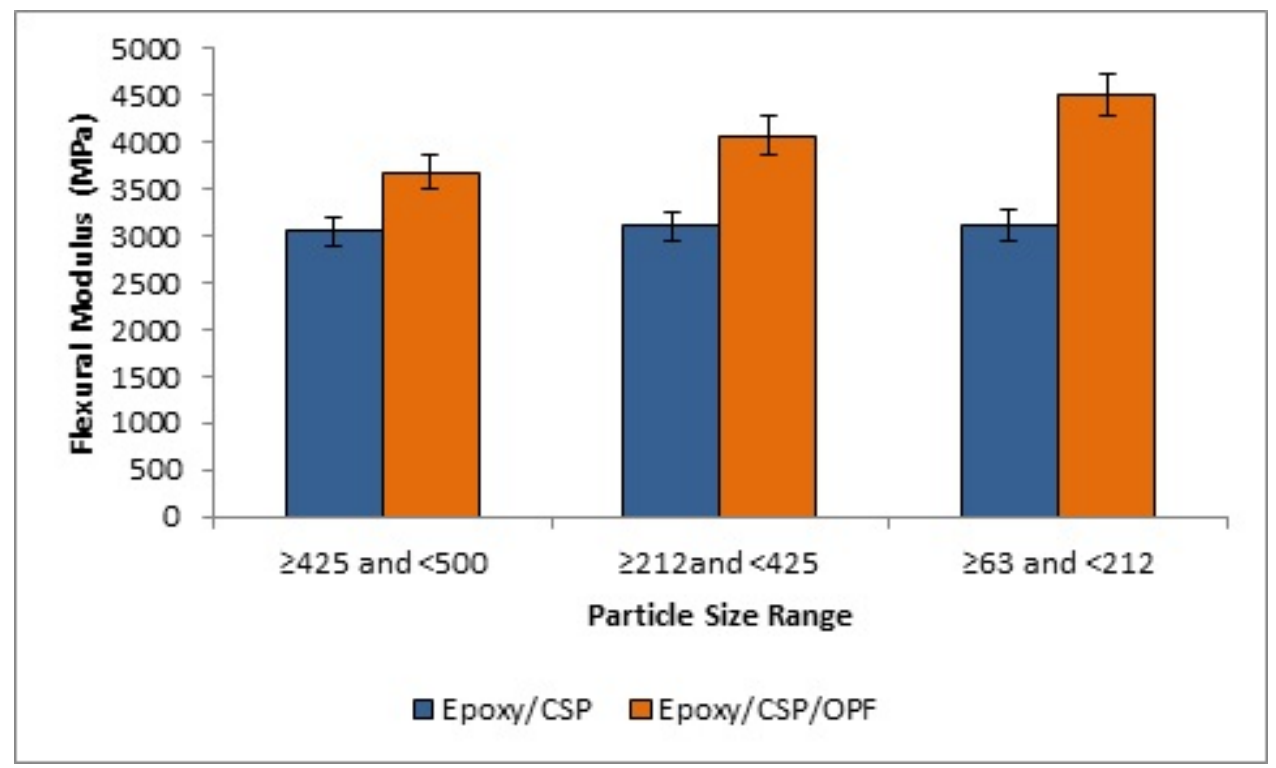

Figure 9: Flexural modulus of epoxy composites

The theory behind the tensile and flexural strength of hybrid composite were inversely proportional to the particle size were mainly due to the good interaction between the particle, fibre and matrix with the decreasing of particle size. According to the research by Packham, the quality of interface adhesion for fibre-reinforced composites plays an important character for the strength of particulate composites. The strength of interface adhesion determines the stress transfer between the mechanisms [7]. Furthermore, for well bonded particles composite, the applied stress is able to transfer sufficiently to the particles from the matrix, hence this improves the strength of composite [8]. Besides, the flexural modulus of hybrid composites with particle size in range 1 and 2 had increased $9.6 \%$ and $18 \%$ as compared to hybrid composites in range 3 . As referring to figure 8 , it showed that the tensile modulus of hybrid composite decrease with decreasing the size of cockle shell/oil palm fibre-epoxy composite. The reasons for decrease in strength and modulus were due to the poor interaction caused by the hydrophilic properties of particles and oil palm fibres (some waxy substances, natural fats and impurities were still entrapped on the surface of oil palm fibres after chemical treatment) and the hydrophobic properties of epoxy resin. This poor interaction resulted in debonding of filler and fibres from the matrix. The increase in flexural modulus as shown in figure 9 can be attributed to good interfacial adhesion between constituents of the composite [9].

\subsection{Water Absorption Property}

Figure 10, figure 11 and figure 12 showed the effect of particle size on the percentage of water absorption for the epoxy composites. It was observed that the percentage of water absorption of composites increased constantly with the increasing of immersed time and particle loading for all three different particle sizes. After few days of immersion, "white layer substance" was observed on the top of water surface. The white layer substance became thicker and the void became clearer on the surface of the composites with the increased of immersion time. This was due to the loosing of resin after the long immersion of time, with the loosing of resin which could lead to larger interfacial area between the particle and matrix, hence caused the increasing of water absorption [10]. Besides, high percentage water absorption of composites was due to the hydrophilic nature of natural filler. One of the reasons for higher water absorption at higher particle loading was due to the increasing formation of agglomerations causes by the difficulties of obtaining a homogeneous dispersion of particle within the matrix. The agglomeration of particles could lead to the trapping of air bubbles in the composite. Thus, the capacity of water absorption increases at higher particle loading. By comparing to the figure 10, figure 11 and figure 12, it shows that the composite with particle size in range 1 (smallest particle size in this research) had higher percentage of water absorption than the particle size in range 2 composite and 3 composite. This happened because smaller particle size has higher total surface area which leads to increase of water uptake. 


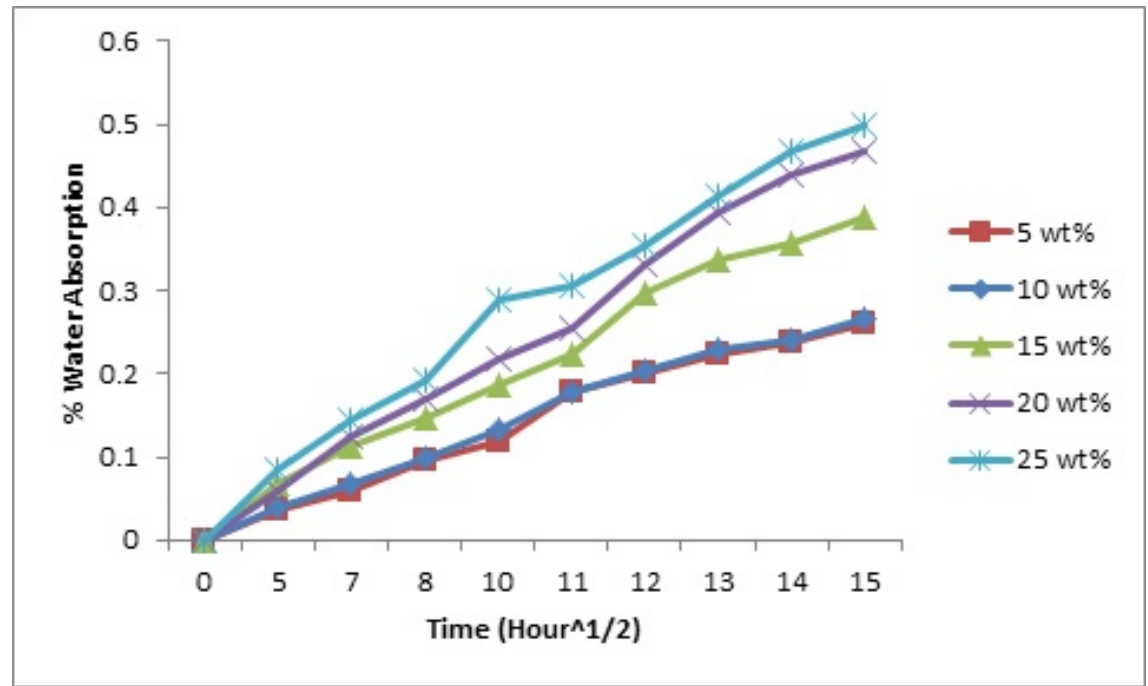

Figure 10: Water absorption versus square root of hours $(\geq 63$ and $<212(\mu \mathrm{m})$

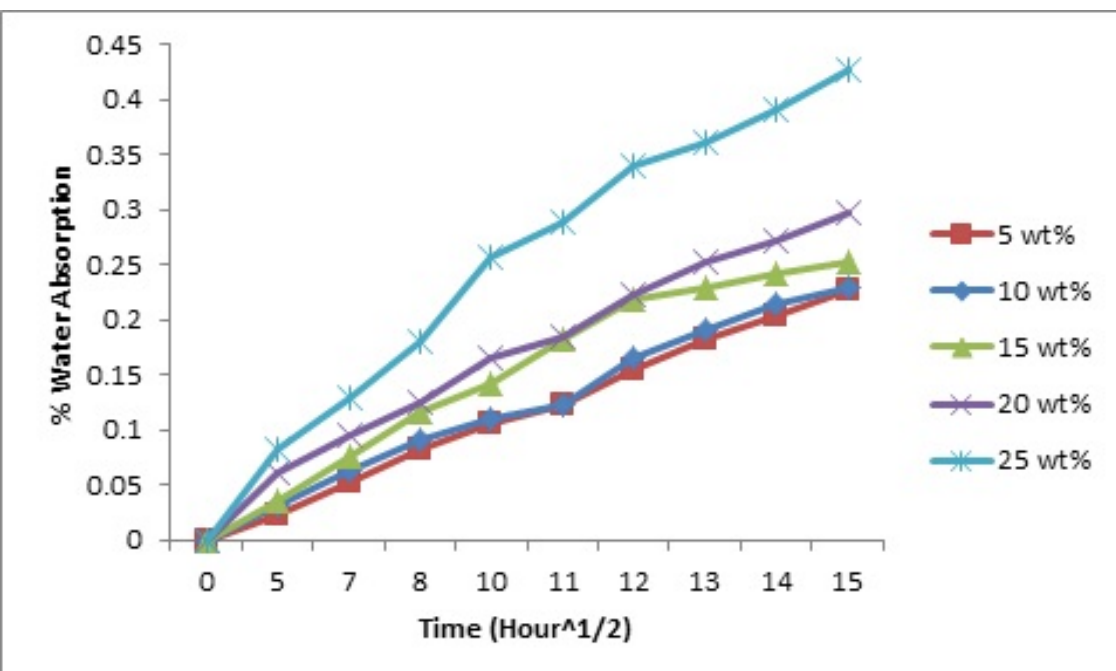

Figure 11: Water absorption versus square root of hours $(\geq 212$ and $<425(\mu \mathrm{m})$

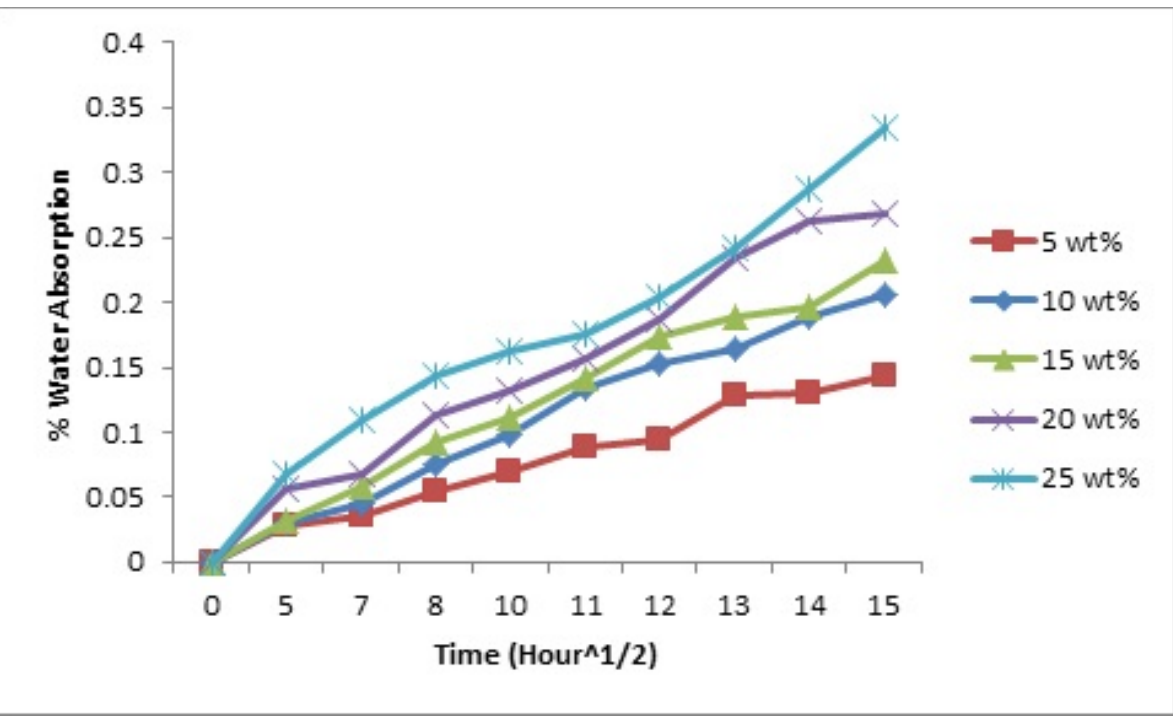

Figure 12: Water absorption versus square root of hours $(\geq 425$ and $<500(\mu \mathrm{m})$ 


\subsection{Morphology Property}

Referring to Figure 13(a), it can be observed that the cockle shell particle-epoxy composite with size in range 1 ( $\geq$ 62 and $<212(\mu \mathrm{m})$ had good dispersion of particles, as it also can be seen that the particles was surrounded by epoxy resin. This indicating good dispersion of particles filled epoxy resin in the composite, thus resulting in good particlematrix adhesion. As referring to figure 13(b), the cockle shell particle-epoxy composite with size in range 3 ( $\geq$ 425 and $<500(\mu \mathrm{m})$ experienced agglomeration between the particles in the composite, this represent poor interface adhesion between the particle and matrix, thus lead to debonding of particle in this composite. In Figure 14, it can observe that the oil palm fibre reinforced epoxy composite experienced fibre pull out. Moreover, it also showed that the oil palm fibre composite experienced poor distribution of fibre and the present of void in the composite thus caused debonding to occur and finally leads to decrease in mechanical properties.
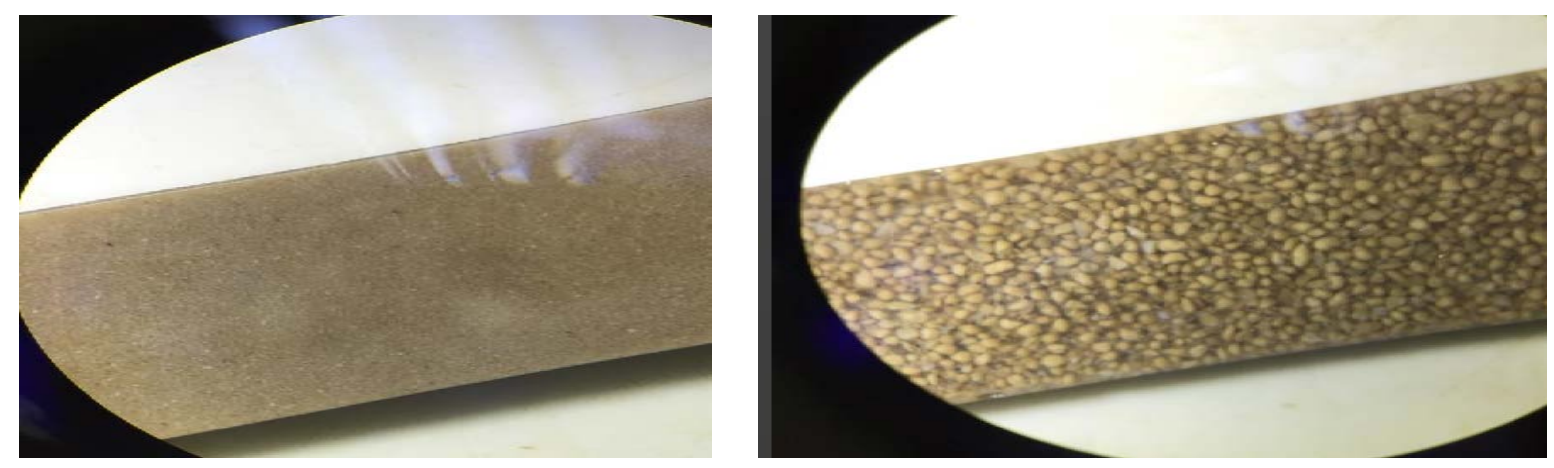

Figure 13: Optical microscope image of cockle shell particle epoxy composite with size in (a) Range 1 ( $\geq 62$ and $<$ $212 \mu \mathrm{m})$, and (b) Range $3(\geq 425$ and $<500 \mu \mathrm{m})$

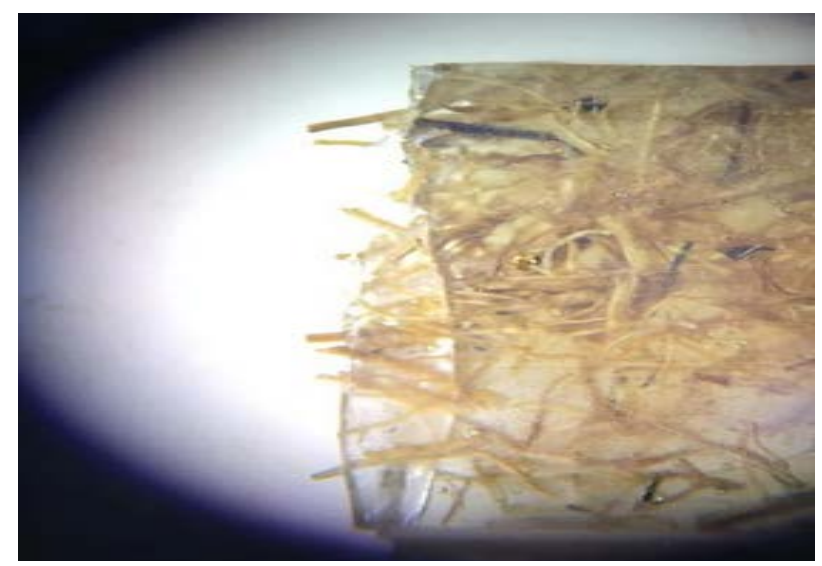

Figure 14: Optical microscope of cockle shell particle and oil palm fibre reinforced epoxy composite

\section{CONCLUSIONS}

The summary is as follows:

- The results show a major improvement in mechanical properties with the decreasing of particle size and particle loading.

- The young's modulus of cockle shell particle-epoxy composite was observed to be increased with increasing particle loading.

- For hybrid composite, it was observed that the tensile and flexural strength increase with decreasing particle size.

- Morphology analysis showed that smaller size of cockle shell particles composite had good dispersion of particle compared to larger size of particles.

- The strength of composites is strongly affected by the particle size and loading. 


\section{ACKNOWLEDGEMENT}

The researchers would like to thank the Curtin University Sarawak for providing the research grant (CSRF) that has made this work possible

\section{REFERENCES}

1. Supaphorn, T., Yamada, K., Leong, Y. W. \& Hamada, H. (2011). Development of Cockleshell-Derived $\mathrm{CaCO}_{3}$ for Flame Retardancy of Recycled PET/Recycled PP Blend. Materials Sciences and Applications, 2, 59-69.

2. Yuhazri, M. Y., Phongsakorn, P.T. \& Haeryip, S. (2010). A Comparison Process between Vacuum Infusion and Hand Lay-Up Method toward Kenaf/Polyster Composites. International Journal of Basic \& Applied Sciences, 10(3), 54-57.

3. Behzad, K. (2011). Effect of calcium carbonate as mineral filler on the physic and mechanical properties of wood based composites, World Applied Science Journal, 13(1), 129-132.

4. Arrakhiz F. Z., El Achaby M, Malha M, Bensalah M.O., Fassi-Fehri, O., Bouhfid, R. (2012). Mechanical and thermal properties of natural fibres reinforced polymer composites: doum/low density polyethylene. Materials and Design, 43, 200-205.

5. Li, Y., Pickering, K. L. (2008). Hemp fibre reinforced composites using chelator and enzyme treatments. Composites Science and Technology, 68(15), 3293-3298.

6. Packham, D. E. (2001). Work of adhesion: contact angles and contact mechanics. International Journal of Adhesion and Adhesives, 16(2), 121-128.

7. Nakamura, Y., Yamaguchi, M., Okubo, M. \& Matsumoto, T. (1992). Effect of particle size on mechanical properties of epoxy resin filled with angular-shaped silica. Journal of Applied Polymer Science, 44(1), 151-158.

8. Gu, J., Ma, L., Gan, M., Zhang, F., Li, W. \& Huang, C. (2012). Preparation and thermal properties of poly (2,3dimethylaniline)/ZrO 2 composite. Thermochimica Acta, 549, 13-16.

9. Hussein, A. A., Salim, R. D. \& Sultan, A. A. (2011).Water Absorption and Mechanical Properties of High Density Polyethylene/ Egg shell Composite, Journal of Basrah Researches (Sciences), 37(3A), 15.

10. Shuhadah, S., \& Kamaruddin (2008). Thermal Analysis, Water Absorption and Morphological Properties of Egg shell Powder filled Low Density Polyethylene Composites, Proceedings of MUCET, UniMAP, Kangar, Perlis, 1516. 